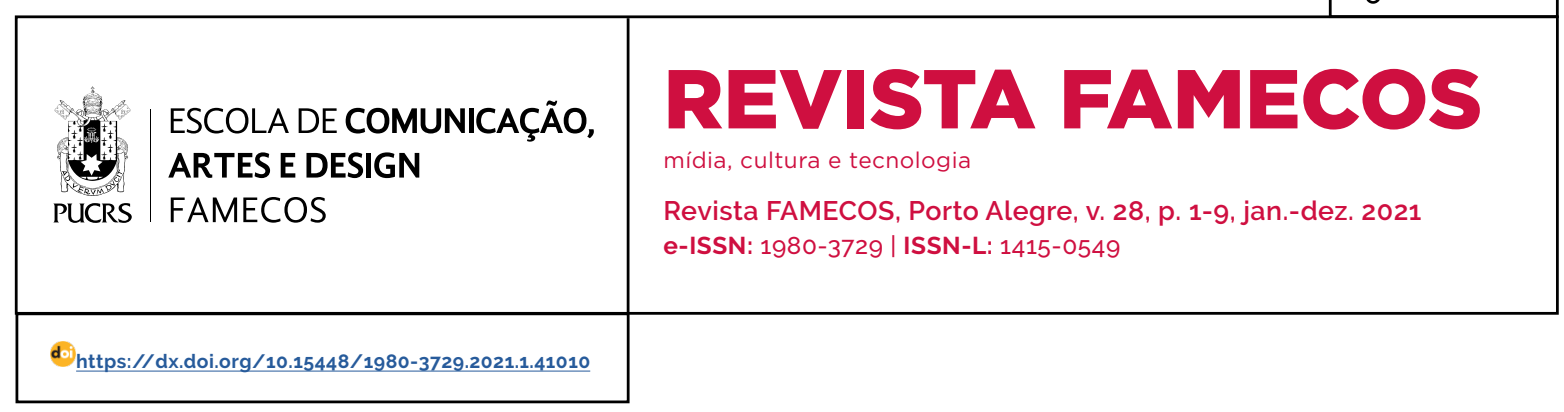

VARIA

\title{
Processos de subjetivação e acontecimento comunicacional
}

\author{
Subjectivation processes and communicational event \\ Procesos de subjetivación y evento comunicacional
}

\author{
José Isaias Venera ${ }^{1}$ \\ orcid.org/0000-0002-9220-446X \\ j.i.venera@gmail.com
}

Recebido em: 28 maio 2021. Aprovado em: 21 out. 2021. Publicado em: 14 dez. 2021.
Resumo: Com este artigo, busca-se demarcar uma perspectiva teórica para os estudos da comunicação com base nos processos de subjetivação. No trabalho, desenvolvem-se as noções de acontecimento e de comunicação que integram a Nova Teoria da Comunicação, de Ciro Marcondes Filho, e procura-se acentuar os estudos que abordam questões da subjetividade. O que justifica esse olhar comunicacional é o pressuposto de um conceito que mobilize os modos de constituição de si. O objetivo é articular um conceito de comunicação cujo centro não é o media, mas o processo e, nele, os modos de constituição do sujeito. A pesquisa bibliográfica tem referencial teórico pós-estruturalista. Conclui-se que a articulação do campo da comunicação com as questões da subjetividade depende de um olhar específico fundamentado em um conceito comunicacional pelo qual se desenvolve a articulação.

Palavras-chave: Comunicação. Processos de subjetivação. Sentido.

Abstract: With this article, we seek to demarcate a theoretical perspective for the studies of communication based on the notions of subjectivation processes. The work starts from the notions of event and communication that integrate the New Theory of Communication, by Ciro Marcondes Filho, and tries to highlight studies that deals with the subjectivity. The assumption of a concept of communication that mobilizes the subjectification process of itself is what justifies this communicational perspective. The objective is to articulate a concept of communication whose center is not the media, but the process and its modes of subjectification. The bibliographic research has a post-structuralist theoretical framework. It is concluded that the articulation of the field of communication with the subjectivity points needs a specific look from a communicational concept.

Keywords: Communication. Subjectification processes. Sense.

\section{Introdução}

O desafio deste trabalho é demarcar uma perspectiva teórica no campo da comunicação para os processos de subjetivação, no recorte dos estudos que podem ser classificados como pós-estruturalistas, ${ }^{2}$ cuja caracteristica comum é questionar o conceito de sujeito autônimo e transparente a si mesmo. No campo da comunicação, ganha importância

\section{(c) (i)}


a Nova Teoria da Comunicação, desenvolvida por Ciro Marcondes Filho (2013), que articula autores como Henri Bergson e Gilles Deleuze na construção de um conceito de comunicação que permite a aproximação com o tema da subjetividade.

A área da comunicação pode ser demarcada historicamente tanto pelas condições técnicas e tecnológicas, com destaque para os avanços dos processos de reprodutibilidade a partir do século XIX, quanto pelos primeiros estudos propriamente do campo, no periodo entreguerras do século XX, sobressaindo Harold Lasswell. Tal período foi nomeado pelo filósofo Michel Foucault (1987) como sociedade disciplinar, e nela os meios de comunicação funcionam como um farol que controla e disciplina o sentido sobre a realidade (VENERA, 2020)

No Brasil, sobretudo a partir dos anos 90 do século passado, essa perspectiva teórica pós-estruturalista, que articula autores como Foucault, Deleuze, Guattari, Derrida e Lyotard, ganhou espaço no campo da comunicação. Arlindo Machado, por exemplo, em seu artigo de 1990 "Máquinas de vigiar", descreveu que a nossa sociedade é menos dos espetáculos (Debord) ${ }^{3}$ e mais da vigilância (Foucault), e cujas câmeras (de vigilância) "se distribuem como uma rede sobre a paisagem social, ocupando todos os espaços e os submetendo ao seu poder de invasão branca, à sua penetração invisivel e indolor" (MACHADO, 1990, p. 24).

Na leitura de Machado (1990) sobre a naturalização (o que não deixa de ser um modo de subjetivação) do sistema de vigilância da sociedade no início do século XX, o debate já se voltava mais para um movimento desejante do sujeito no sistema, no qual a vigilância fica ainda mais invisivel, camuflada no passo a passo dos algoritmos que compõem os territórios virtuais da internet. Essa nova realidade que sobressai no tempo presente foi bem descrita pelo artista plástico Edmond Couchot, em seu livro A tecnologia na arte, de 1998, sobre o qual Machado (2001) observa:
Couchot busca exprimir uma outra experiência de subjetividade, aquela que deriva não de uma vontade, de um desejo, de uma iniciativa de um sujeito "real" (seja ele, novamente, um autor, um espectador ou um "narrador" pressuposto, interno à diegese), mas dos automatismos do dispositivo técnico, "questão chave - explica ele - num momento em que o numérico parece, aos olhos de muitos, desapossar o criador de toda singularidade e de toda expressividade e reduzir o ato criador* aos puros automatismos maquínicos".

O automatismo maquínico na criação, observado por Couchot (1998 apud MACHADO, 2001), aponta para procedimentos técnicos e tecnológicos que atuam na subjetividade. Para usar os termos de Couchot (1998 apud MACHADO, 2001), o automatismo maquínico inscreve-se no "sujeito-nós", e o modo como cada sujeito se implica nesse nós diz respeito ao "sujeito-eu". O tema da subjetividade no presente, marcado pelas interações via internet, vem dessa trama do automatismo maquínico como um modo próprio de subjetivar-se.

Como podemos pensar esse presente que se diferencia de outras épocas sobretudo pela onipresença das relações em rede, pelo recorte do campo da comunicação e dos processos de subjetivação? Essa questão justifica esta investigação, de tornar mais explícita uma leitura comunicacional dos processos de subjetivação, e não simplesmente de basear-se em uma noção de subjetividade que poderia ser aplicada ao campo.

O estudo parte de um conceito de comunicação cujo centro não é o media, mas uma articulação que caracteriza o acontecimento comunicacional, abrindo caminho para os processos de subjetivação. Para isso, desenvolve-se uma noção de comunicação que faz produzir um objeto, aproximando-se dos processos de subjetivação.

\section{Acontecimento comunicacional}

No primeiro volume da Nova Teoria da Comunicação, O rosto e a máquina, Ciro Marcondes Filho (2013) elabora variações para o conceito de comunicação com base na tradição aberta

\footnotetext{
3 Esse não é um debate pacificado, Ferrara (2011) articula os conceitos espetáculo e dispositivo, aproximando as noções, em um caminho diferente do apontado por Machado (1990). Mesmo que sua articulação com a noção de dispositivo tenha como referência principal Giorgio Agamben, o filósofo italiano elabora sua teoria a partir de Foucault, evidentemente, marcando, também, sua diferença.
} 
pelo filósofo Henri Bergson. A comunicação, para Marcondes Filho (2013), pressupõe o que se busca articular neste artigo: os processos de subjetivação, ou os modos de constituição de si. Para colocar o tema da subjetividade no campo da comunicação ao estilo de Foucault (1985), as investigações voltam-se para as práticas pelas quais nos tornamos sujeitos.

Marcondes Filho (2011) em O princípio da razão durante, ao apresentar o olhar de Foucault à comunicação, desenvolve o conceito de acontecimento, que remete à tradição estoica, aproximando-se também da teoria de Gilles Deleuze (2006). Para sustentar essa articulação, o autor defende a tese de Margarida Gouvêa, em que o acontecimento em Foucault segue a teoria estoica dos incorpóreos: "Seres reais entram em relação com outros seres reais e podem, por meio desta relação, se modificar" (MARCONDES FILHO, 2011, p. 87).

Para a teoria dos incorpóreos se integrar à sua pesquisa sobre o acontecimento na comunicação, lemos: "Os signos, em Foucault, são vazios e seu sentido é preenchido pelo acontecimento" (MARCONDES FILHO, 2011, p. 88). É nesse plano dos acontecimentos que o sentido, materializado nos signos, ganha forma, mas enquanto efeito. Machado (2009, p. 303) elucida a noção, cujo princípio está nos estoicos: "O incorpóreo, ou a ideia, não é a causa elevada, a causa transcendente, mas um efeito superficial". O incorpóreo não está na ordem das causas transcendentais (como na teoria platônica), mas sim nos efeitos produzidos nas misturas de corpos.

Em Theatrum philosophicum (2005), com referência a duas obras de Deleuze, Diferença e Repetição (1988) e Lógica do Sentido (2006), Foucault acentua que o acontecimento é tomado como um incorpóreo no limite dos corpos. Sua materialidade se expressa na teia discursiva, como efeito. Em uma passagem que se volta mais à divisão platônica (original e simulacro), o tema que nos interessa fica ainda mais explicitado:

submergindo a aparência, rompendo os seus ligamentos com a essência, aparecerá o acontecimento; expulsando o peso da matéria, aparecerá o incorporal; rompendo o círculo que imita a eternidade, a insistência intemporal; purificando-se de todas as misturas com a pureza, a singularidade impenetrável; afastando a falsidade da falsa aparência, a aparência mesma do simulacro (FOUCAULT, 2005, p. 80-81).

Colocar a centralidade do acontecimento na comunicação pressupõe uma dimensão metodológica, na qual será preciso rejeitar todas as hipóteses sobre o objeto de pesquisa. O modo como um processo comunicacional se forma, na mistura dos corpos, define o sentido. O sentido não está subordinado há um valor preestabelecido, há uma posição de cópia na transmissão de um conteúdo, mas aponta para o simulacro (ou incorpóreo), ou seja, para a diferença em curso.

Para trazer um exemplo de vigilância dos discursos que buscam subordinar um valor ao modo como a realidade se apresenta, é o que se convencionou chamar de polarização política no Brasil. Operar a partir de oposições é uma tentativa de estabilizar a interpretação sobre a realidade, de territorializar o sentido, ao passo que seria nas microrrelações (nas misturas de corpos) que o sentido adquire sua dimensão de acontecimento em uma produção incessante da diferença.

A comunicação enquanto acontecimento aponta para a diferença que a constitui. Ferrara (2021, p. 9) apresenta uma epistemologia da diferença para o campo da comunicação, na qual ela (a diferença) "se apresenta de modo empírico e se faz reconhecer através de uma potência de ser comunicante, porém, sem intencionalidade ou objetivos estabelecidos". Nessa direção, conter a diferença apresenta-se como um gesto de conter a comunicação

Braga (2020, p. 27), ao discorrer sobre a polarização como um processo de apagamento da diferença, diz: "todos os que discordam, hoje, no pais, de uma atitude contraditoriamente denominada 'liberal', se veem imediatamente categorizados em um código polarizador - 'comunistas'. O mesmo tipo de estrutura age no racismo e na homofobia". Na polarização, como reforça Braga (2020, p. 25), "não há debate", o que, trazendo para a discussão que nos interessa, não há produção da diferença em curso, ou, ainda, não há comunicação. 
Nesse pressuposto, pode-se também perceber que as noções de discurso e poder, tão caras a Foucault (1987) tanto na sua fase arqueológica quanto genealógica, seguem o mesmo movimento, cujo sentido não está implícito no signo ou na instituição de poder, mas sim nas múltiplas relações que se estabelecem.

A noção de acontecimento em Foucault tem a ver com certo uso que o filósofo faz dos estoicos, mas não é sua única influência. ${ }^{4}$ Mantendo-se essa aproximação com os estoicos, em A ordem do discurso, o tema aparece com mais clareza:

Se os discursos devem ser tratados, antes, como conjuntos de acontecimentos discursivos, que estatuto convém dar a esta noção de acontecimento que foi tão raramente levada em consideração pelos filósofos? Certamente o acontecimento não é nem substância nem acidente, nem qualidade nem processo; o acontecimento não é da ordem dos corpos. Entretanto, ele não é imaterial; é sempre no âmbito da materialidade que ele se efetiva, que é efeito; ele possui seu lugar e consiste na relação, coexistência, dispersão, recorte, acumulação, seleção de elementos materiais; não é o ato nem a propriedade de um corpo; produz-se como efeito de e em uma dispersão material. Digamos que a filosofia do acontecimento deveria avançar na direção paradoxal, à primeira vista, de um materialismo do incorporal (FOUCAULT, 1996, p. 57-58).

Em Foucault (1996), o que está em questão nesse momento é o acontecimento discursivo e histórico (arqueologia), e este permite-se, no nosso campo, relacionar com o acontecimento comunicacional, cuja diferença está em demarcar as condições de possibilidade de produção do discurso e os modos como o sujeito se constitui nas relações que estabelece.

Em Deleuze, o acontecimento na tradição estoica ganha centralidade em Lógica do sentido (2006), ou seja, o acontecimento enquanto sentido em um movimento paradoxal: "Parece-nos que o acontecimento, isto é, o sentido, relaciona-se a um elemento paradoxal intervindo como não-senso ou ponto aleatório, operando como quase-causa e assegurando a plena autonomia do efeito" (DELEUZE, 2006, p. 98). Esse paradoxo é articulado porque o sentido constitui, para o autor, uma entidade não existente, o que marca sua relação com o não-senso, contudo "o não-senso é ao mesmo tempo o que não tem sentido, operando a doação do sentido" (DELEUZE, 2006, p. 74).

Em sintese, faz-se importante demarcar que em Deleuze (2006) o sentido é sempre produzido, ou seja, não é algo a ser descoberto, revelado, restaurado (porque sua produção se dá na relação com o não-senso). Se ele se faz nas relações, significa que não há sentido a priori, fazendo com que toda busca por determinado significado sobre as coisas se constitua na própria condição de fabricação do sentido, marcando também o acontecimento.

Já na sua parceria com Guattari, o tema, para Deleuze, manteve-se importante:

\begin{abstract}
O acontecimento não é de maneira nenhuma o estado de coisas, ele se atualiza num estado de coisas, num corpo, num vivido, mas ele tem uma parte sombria e secreta que não para de se subtrair ou de se acrescentar à sua atualização: contrariamente ao estado de coisas, ele não começa nem acaba, mas ganhou ou guardou o movimento infinito ao qual dá consistência (DELEUZE; GUATTARI, 1992, p. 201).
\end{abstract}

Há nessa definição de acontecimento um processo contínuo de transformação, modificação, multiplicação que, em parte, se atualiza num estado de coisas e, em outra, não se deixa atualizar completamente. É nesta direção o projeto de Marcondes Filho, de pensar uma nova teoria da comunicação, a qual poderiamos também nomear de teoria do "acontecimento comunicacional", pressupondo um processo de transformação contínuo.

Marcondes Filho (2013, p. 41) objetiva essa noção: "Não existe seres, apenas acontecimentos. Essa afirmação sugestiva, originada da interpretação do pensamento de Heráclito, está na base da nossa teoria da comunicação, tanto interpessoal como de massa e por internet". O acontecimento é o efeito produzido na relação, ou o choque entre coisas (seres vivos, inanimados, fatos simbólicos

\footnotetext{
4 Como podemos ver em A arqueologia do saber (2013) e em Nietzsche, a genealogia e a história (1992), tem relação com a irrupção de singularidades que marcam nossa atualidade.
} 
etc.). Quando trazemos essa compreensão para os estudos voltados aos processos de subjetivação, ou modos de constituição de si, implica dizer que é nas relações sociais e comunicacionais que se produzem modos de constituição de si, seja pelo recorte do gênero, seja pelo de raça, de classe social etc.

Em Das coisas que nos fazem pensar, Marcondes Filho (2014, p. 80) mostra que a Nova Teoria da Comunicação "toma o acontecimento como um de seus pilares, junto com outros conceitos estruturantes como alteridade, sentido, movimento, além-linguístico, razão 'entre' e razão 'durante'". A pergunta que o autor faz e que se torna importante para esse momento é: em que medida o acontecimento comunicacional difere do geral? Para o autor, está implicado o traço comunicacional no conceito filosófico de acontecimento, levando-se em conta que comunicar pressupõe "mudar de posição, passar a pensar diferentemente, ser afetivamente tocado, mexido, alterado pelo outro" (MARCONDES FILHO, 2014, p. 81).

Mesmo que comunicação pressuponha acontecimento geral, há também diferenças, sugerindo especificidades do campo, o que aponta para investigar o que está em jogo entre emissor e receptor, ao que se produz dessa relação.

\section{Afecção no centro do conceito de comunicação}

Para explicar o acontecimento comunicacional, Marcondes Filho (2013) dá relevância à noção de afecção, com base em Bergson. O que está fora do sujeito, ${ }^{5}$ chamamos de percepção pura, e, quando esta é percebida, uma mistura se inicia, ou uma "impureza" se forma, transformando a percepção em afecção. O que é percebido afeta o corpo e a mente (a afecção seria assim o plano no qual os incorpóreos circulam).

Conforme Deleuze (2002, p. 56), "afecção remete a um estado do corpo afetado e implica a presença do corpo afetante, ao passo que o afeto remete à transição de um estado a outro, tendo em conta variação correlativa dos corpos afetantes". Marcondes Filho (2013) cita o exemplo de um pico de uma agulha, que causa dor, afetando o corpo, que dói, mas também que faz sentir emoções ao perceber o olhar, o toque na pele, a presença da voz da pessoa que aplicou a picada.

Nesse passo inicial, temos as percepções pura e impura. Na segunda a mistura se faz com a lembrança de outras experiências abrindo caminho para as afecções menos intensas, as representações. Quando se sente uma picada de agulha, podem vir à mente lembranças de infância de idas ao dentista e o medo que essa experiência causava.

Essa descrição do processo inicial vem mais como um caminho para compreender o fenômeno, ao passo que ele se efetua em um espaço-tempo impercebido, mas que atinge o espírito - como atribuído por Bachelard (1993), de um campo de sentido já demarcado -, produzindo um efeito na mente.

Esse primeiro passo dá as bases para Marcondes Filho (2013) ampliar o conceito de comunicação, que, em síntese, parte de um acontecimento que se efetua em um tempo. Começa como uma percepção pura, como em um vídeo no YouTube, que afeta a retina e os tímpanos, demarcando uma primeira fração do tempo desse acontecimento. Dessas intensidades puras (o vídeo e o corpo afetado), produz-se a afecção, a qual podemos nesse momento apontar como uma linha de força inicial no processo de subjetivação. Nessa dobra do fora para o dentro (percepção pura para impura), coisas e seres misturam-se.

Nessa via, para haver comunicação é preciso sair do nivel da informação, ou ao menos que o percebido produza alterações nos sentidos já cristalizados no sujeito, abrindo-se, assim, para um acontecimento comunicacional. O ponto central dessa discussão é que a comunicação pressupõe um acontecimento, ou, para dizer de outra forma, um processo de subjetivação, uma abertura para instituir o sujeito em um devir. 


\section{Sujeito, subjetividade e modos de subjetivação}

Em Foucault (1987), o sujeito é resultado de "modos de subjetivação", isto é, práticas, técnicas, exercicios em determinado campo institucional ou formação social. No campo da educação, mesmo este não sendo uma temática especifica de Foucault, mas que adquire importância em Vigiar e punir (1987), podemos observar que a institucionalização da educação ocidental se inscreve no grande projeto disciplinar da modernidade. A disciplina do corpo (postura, higiene, hierarquia etc.) e da alma (os saberes curriculares) faz da educação um processo de "adestramento" do sujeito. A educação torna-se um dispositivo disciplinar da sociedade.

Esses modos de subjetivação são estudados historicamente, como o sujeito moderno, resultado da sociedade disciplinar. Compete aqui falar da forma-sujeito que se baseia em um projeto de vigilância, o panóptico, e fundamentado no qual Foucault (1987) desenvolveu a arqueogenealogia da sociedade disciplinar.

Foucault (1987) desenvolveu uma longa análise do projeto do filósofo inglês Jeremy Bentham, o panóptico, de 1785, para com ele mostrar como os dispositivos da modernidade, iniciando-se com as prisões e estendendo-se para as fábricas, as escolas, os manicômios etc., tinham como função produzir sujeitos úteis, à época, ao Estado e à produção. São dispositivos ${ }^{6}$ (como a escola) que articulam práticas não discursivas (como as arquiteturas) e discursivas (os saberes curriculares) na produção de sujeitos, ou melhor, de processos de assujeitamento.

Não distante, a origem da sociedade de massa, no século XIX, e dos meios de comunicação de massa, sobretudo no século $X X$, segue esse princípio subjacente da sociedade disciplinar. $\mathrm{Na}$ comunicação, este:

[...] se daria pela disciplina do olhar (classificando e selecionando o que se deve ver, como se os jornais fossem o grande farol que ilumina o interior das casas e dos estabelecimentos) e pelo controle dos sentidos (como se deve interpretar a realidade e as emoções que devem ser despertadas - paixão, cólera etc.) (VENERA, 2020, p. 9).

A midia de massa passou a ser o farol que ilumina certos aspectos da realidade, produzindo discursos que implicam sujeitos no sentido de dizer como devem ser e estar no mundo. Nesse recorte, a TV foi a principal midia, com apresentadores, jornalistas, publicitários, atores, atrizes, ou seja, um conjunto de sujeitos que fazem circular também discursos da medicina, da política, da psicologia etc., demarcando uma cartografia de como cada telespectador deveria cuidar de si, como deveria comportar-se, como os cidadãos deveriam agir numa disputa eleitoral, ou como ser jovem, o que compete a uma mulher, ou ainda, quais atributos um homem deve desenvolver.

No texto "Mídia e produção do sujeito", Fischer (2000, p. 111) faz referência a Derrida, que chegou "a afirmar que as coisas que realmente importam são aquelas enunciadas na mídia". Hoje poderíamos agregar a esta a mídia de rede, conectada à internet, sem desconsiderar a relevância que os meios de comunicação de massa ainda exercem na sociedade.

Mas um dilema se apresenta entre, por um lado, os processos dominantes de comunicação que buscam impelir o sujeito a se constituir de determinado modo e, por outro, como de fato se constitui a subjetividade. Dilema de um processo coletivo para o individual. A pergunta que devemos fazer agora é: o que é subjetividade? O filósofo José Gil (2009), na perspectiva deleuziana, define a subjetividade como certo poder de afetar a si próprio. Para ele, a "subjectividade é a força de se auto-afectar. Mas esta força é induzida no sujeito a partir do fora" (GIL, 2009, p. 24). A passagem do fora para o dentro, chamamos de dobra.

A subjetividade constitui-se em certo modo de produção, ou seja, em um processo de subjetivação. O gênero é uma categoria que serve de exemplo. Reduzir o gênero ao binarismo sexual é negar a diferença. $O$ discurso dominante sobre o gênero

\footnotetext{
6 A noção de dispositivo no campo da comunicação foi muito bem desenvolvida pelos trabalhos de José Braga, com destaque para "Interagindo com Foucault. Os arranjos disposicionais e a comunicação" (2018) e "Uma conversa sobre dispositivos" (2020).
} 
exerce poder sobre os indivíduos, marcando uma dobra de subjetivação, mas, nesse caso, pela via do assujeitamento. Mesmo assim, cada sujeito se implica, à sua maneira, com esses processos dominantes. Os discursos podem também ser interpretados como linhas de força com base nas quais os processos de assujeitamento e subjetivação se formam: assujeitamento para os processos dominantes que negam a diferença, e subjetivação para os processos de proliferação da diferença.

Como exemplo, tem-se o movimento \#EleNão, de 2018, como um campo de força produzido em relação aos discursos de negação da diferença. Tanto a proliferação de novos usos da sexualidade quanto as múltiplas formas de viver e de ser mulher são linhas de fuga no que se refere aos territórios subjetivos dominantes.

De um lado, estão os discursos que circulam e, de outro, o modo como cada sujeito se implica com uma ordem discursiva. Entre um e outro há uma dobra, um modo de constituição de si. Em uma pesquisa realizada em $2019^{7}$ de análise dos posts do grupo fechado do Facebook "Mulheres Unidas com o Brasil", que se origina do movimento \#EleNão, observou-se que o coletivo de mulheres funciona, entre outras expressões, como uma relação de poder em curso, mobilizado pelo sentimento de (des)amparo. Diante de um governo federal que nega a diferença (mobiliza o afeto de desamparo), o coletivo de mulheres faz circular afetos, como na expressão que ficou conhecida "Ninguém solta a mão de ninguém".

\section{Sujeito como efeito do saber e do poder}

Em um importante artigo, "O sujeito e o poder", o filósofo Michel Foucault (1985) elucida o modo como o sujeito se constitui pelas relações de poder: "Pareceu-me que, enquanto o sujeito humano é colocado em relação de produção e de significação, é igualmente colocado em relações de poder muito complexas" (FOUCAULT, 1985. p. 232). O ponto de interesse sobre a questão do poder é investigar como o sujeito se constitui na relação com as palavras e as coisas, "como se exerce" nas relações, ou seja, como ele se constitui nessas práticas sociais e discursivas

Esse caminho abre-se para os estudos comunicacionais de investigar não as coisas, como os meios de comunicação, nem o sujeito isoladamente, mas as relações que se estabelecem e por meio das quais o sujeito se constitui no acontecimento comunicacional. Esse é o ponto de maior interesse para o campo da comunicação, ao menos nessa via, de investigar como o sujeito se constitui no acontecimento comunicacional.

Nos processos de comunicação, entende Foucault (1985, p. 240), há "sempre uma certa forma de agir sobre o outro ou os outros. Porém, a produção e a circulação de elementos significantes podem perfeitamente ter por objetivo ou por consequência efeito de poder". Os processos de comunicação adquirem certa importância para o filósofo, mesmo que não tenham sido um dos seus temas especificos.

O autor apresenta três tipos de relação que estão implicados no exercício do poder: "relações de poder", "relações de comunicação" e "capacidades objetivas". Essa separação não deve ser entendida como três domínios separados, como se houvesse,

de um lado, o domínio das coisas, da técnica finalizada, do trabalho e da formação do real; e do outro, o dos signos, da comunicação, da reciprocidade e da fabricação do sentido: enfim, o domínio dos meios de coação, de desigualdade e de ação dos homens sobre os homens (FOUCAULT, 1985, p. 240-241).

Observa-se que os sentidos, como os produzidos sobre as mulheres, os negros, os LGBTQIA+, os pobres etc., se dão pelo conjunto dessas relações. Ou seja, as "técnicas (da transformação do real), do domínio da comunicação (da fabricação dos sentidos) e do domínio de coação (de ação dos homens sobre os homens) não se apresentam necessariamente de forma uniforme e constante" (SARGENTINI, 2015, p. 20).

No jornalismo, há o domínio da técnica de produção - o jogo da comunicação, o que implica a

\footnotetext{
7 Projeto desenvolvido na Universidade da Região de Joinville (Univille) em 2019 que resultou no artigo "Mulheres Unidas com o Brasil: net-ativismo, gênero e amparo" (VENERA et al., 2021)
} 
relação entre imagens, textos, sons, áudio, cores, texturas, formatos etc. (fabricação dos sentidos) - e, na circulação, as relações de poder (o modo como a forma jornalismo assujeita e/ou subjetiva os receptores).

Nesses três domínios explicitados por Foucault (1985), vemos articulada a perspectiva da noção de dispositivo e como nela estão mobilizadas as noções de poder e saber. Assim, os campos da publicidade e propaganda, das relações públicas e do jornalismo são racionalidades específicas, práticas disciplinares que engendram determinadas relações de poder.

Para alinhar o tema do saber e do poder mais diretamente com os processos de subjetivação, Castro traz uma citação pertinente de Foucault: "Antes tratei de produzir uma história dos diferentes modos de subjetivação do ser humano em nossa cultura; tratei, nesta ótica, de três modos de objetivação que transformam os seres humanos em sujeitos" (FOUCAULT apud CASTRO, 2009, p. 324). Os três modos de objetificação são o saber, o poder e o sujeito, ou, para dizer de outra forma, os discursos que engendram práticas (como nos campos profissionais da comunicação), as relações de poder com base nas instituições e o modo como o sujeito se constitui por meio dessas relações.

\section{Considerações finais}

Nesse percurso teórico foi evidenciada a relação de um conceito de comunicação com base na Nova Teoria da Comunicação, que em si já consta aberta para as análises dos processos de subjetivação. Diante de um tempo em que o automatismo dos algoritmos reforça ainda mais que há uma racionalidade técnica que engendra o mundo, fazem-se ainda mais importantes as análises que colocam o sujeito no centro das reflexões.

A racionalidade técnica, ou, para atualizar o debate na perspectiva foucaultiana, a racionalidade neoliberal - como aparece no curso 0 nascimento da biopolitica (2008) - faz circular discursos cuja função é conter a proliferação da diferença em favor da lógica do mercado. Cabe aos estudos centrados no acontecimento comunicacional acentuar a diferença, as resistências, as relações de poder que são travadas nas práticas discursivas e a partir das quais a própria comunicação se faz, sobretudo, no que escapa as intencionalidades que previamente buscam disciplinar e estancar a proliferação de sentidos.

Assim, processos de subjetivação e acontecimento comunicacional integram uma perspectiva nas investigações, na qual os trabalhos de Ciro Marcondes Filho ganham importância neste debate, acentuando um modo específico de articular autores de outras áreas - entre elas, da filosofia - para operar na especificidade do campo da comunicação.

Se, por um lado, os processos dominantes de racionalidade dão as condições de possibilidade para a produção de determinando tipo de assujeitamento - campo de destaque nos estudos frankfurtianos -, por outro isso não se dá sem resistência (mesmo que em um olhar macro se tenha outra impressão), abrindo caminho para as análises das microrrelações, dos modos de subjetivação mais ligados ao cuidado de si.

A centralidade dos processos de subjetivação nas pesquisas em torno do acontecimento comunicacional é a principal contribuição que se deixa com este trabalho. Para isso, tanto o conceito de comunicação quanto o modo como ele constitui nas relações práticas não se faz sem a diferença em curso; diferença que se efetiva em novos modos de constituição de si.

\section{Referências}

BACHELARD, G. A poética do espaço. São Paulo: Martins Fontes, 1993.

BRAGA, José Luiz. Polarização como estrutura da intolerância: uma questão comunicacional. In: HELLER, Barbara; CAL, Danila; ROSA, Ana Paula da. Midiatização, (in)tolerância e reconhecimento. Salvador: EDUFBA, 2020. p. 19-35.

BRAGA, José Luiz. Interagindo com Foucault. Os arranjos disposicionais e a comunicação. Questões transversais. Revista de Epistemologia da Comunicação, v. 6, n. 12, p. 81-91, jul./dez. 2018.

BRAGA, José Luiz. Uma conversa sobre dispositivos Belo Horizonte: PPGCOM/UFMG, 2020.

CASTRO, Edgardo. Vocabulário de Foucault: um percurso pelos seus temas, conceitos e autores. Belo Horizonte: Autêntica Editora, 2009. 
DELEUZE, Gilles. Espinosa: filosofia prática. São Paulo: Escuta, 2002

DELEUZE, Gilles. Lógica do sentido. São Paulo: Perspectiva, 2006.

DELEUZE, Gilles. Diferença e repetição. Rio de Janeiro: Graal, 1988

DELEUZE, Gilles; GUATTARI, Félix. O que é filosofia? Rio de Janeiro: 34, 1992.

DELEUZE, Gilles; GUATTARI, Félix. Mil Platôs: capitaLismo e esquizofrenia. Rio de Janeiro: 34, 1997.

FERRARA, Lucrécia D'Alessio. A comunicação como espetáculo e dispositivo epistemológico. Signo y pensam, Bogotá, v. 30, n. 58, p. 40-51, jun. 2011

FERREARA, Lucrécia D'Alessio. A epistemologia da diferença. In: ANAIS DO ENCONTRO ANUAL DA COMPÓS, 30., 2021, São Paulo. Anais eletrônicos [...]. Campinas: Galoá, 2021. Disponivel em: https:// proceedings.science/compos/compos-2021/paper$\mathrm{s} / \mathrm{a}$-epistemologia-da-diferenca?lang=pt-br. Acesso em: 19 nov. 2021

FISCHER, Rosa Maria Bueno. Mídia e produção do sujeito: o privado em praça pública. In: FONSECA, Tânia Mara Galli; FRANCISCO, Deise Juliana (org.). Formas de ser e habitar a contemporaneidade. Porto Alegre: Ed. UFRGS, 2000. p. 109-120.

FOUCAULT, Michel. A ordem do discurso. São Paulo: Loyola, 1996.

FOUCAULT, Michel. O sujeito e o poder. In: DREYFUS, Hubert; RABINOW, Paul (org.). Michel Foucault: uma trajetória filosófica. Rio de Janeiro: Forense Universitária, 1985. p. 231-249

FOUCAULT, Michel. Vigiar e punir: nascimento da prisão. Petrópolis: Vozes, 1987.

FOUCAULT, Michel. Arqueologia do saber. 8. ed. São Paulo: Martins Fontes, 2013

FOUCAULT, Michel. Nietzsche, a genealogia e a história. In: FOUCAULT, Michel. Microfísica do poder. Rio de Janeiro: Graal, 1992. p. 15-37

FOUCAULT, Michel. Nascimento da biopolítica. São Paulo: Martins Fontes, 2008.

GIL, José. Em busca da identidade: o desnorte. Lisboa: Relógio D'Água, 2009.

MACHADO, Arlindo. Máquinas de vigiar. Revista USP São Paulo, n. 7. p. 23-32, 1990

MACHADO, Arlindo. O sujeito no ciberespaço. In: CONGRESSO BRASILEIRO DA COMUNICAÇÃO, 24., 2001, Campo Grande. Anais eletrônicos [...] Campo Grande, 2001. Disponivel em: http://www.portcom.intercom. org.br/pdfs/2970855069179539421402989710417477 8288.pdf. Acesso em: 22 nov. 2021

MARCONDES FILHO, Ciro. O principio da razão durante diálogo, poder e interfaces sociais da comunicação São Paulo: Paulus, 2011. v. 4. (Nova Teoria da Comunicação, III, tomo IV.).
MARCONDES FILHO, Ciro. O rosto e a máquina: o fenômeno da comunicação visto pelos ângulos humano medial e tecnológico. São Paulo: Paulus, 2013. v. 1. (Nova Teoria da Comunicação).

MARCONDES FILHO, Ciro. Das coisas que me fazem pensar. O debate sobre a Nova Teoria da Comunicação. São Paulo: Ideias \& Letras, 2014

MAY, Todd. Pós-estruturalismo e anarquismo. Rio de Janeiro: Achiamé, [1995?].

SARGENTINI, Vanice Maria Oliveira. Dispositivo: um aporte metodológico para o estudo do discurso. In: SOUZA, Kátia Menezes de; PAIXÃO, Humberto Pires (org.). Dispositivos de poder/saber em Michel Foucault: biopolítica, corpo e subjetividade. São Paulo: Intermeios; Goiânia: UFG, 2015. p. 17-27.

VENERA, José Isaías. O campo da comunicação e do jornalismo em torno dos problemas do poder e da dominação. In: GOLEMBIEWSKI, Carlos (org.). Pesquisa em comunicação: jornal, rádio, TV e redes. Curitiba: Brazil Publishing, 2020. p. 6-15

VENERA, José Isaias.; MATOS, Silvio Simão de; GOLEMBIEWSKI, Carlos; BRUCKHEIMER, L. C. Mulheres Unidas com o Brasil: net-ativismo, gênero e amparo. Paradoxos, Porto Alegre, v. 6, n. 1, p. 103-123, 2021.

\section{José Isaías Venera}

Doutor em Ciências da Linguagem pela Universidade do Sul de SC (Unisul), em Tubarão, SC, Brasil. Professor dos cursos de Comunicação da Universidade da Região de Joinville (Univille), em Joinville, SC, Brasil, e Universidade do Vale do Itajaí (Univali), em Itajaí, SC, Brasil. Integrante do grupo de pesquisa Comunicação, mediações e cultura.

\section{Endereço para correspondência}

Centro de Educação Superior de Ciências Humanas e da Comunicação

Universidade do Vale do Itajaí

Rua Uruguai, 458 - Bloco 10

Centro, 88302-202

Itajaí, SC, Brasil

Os textos deste artigo foram revisados pela Poá Comunicação e submetidos para validação do autor antes da publicação 